
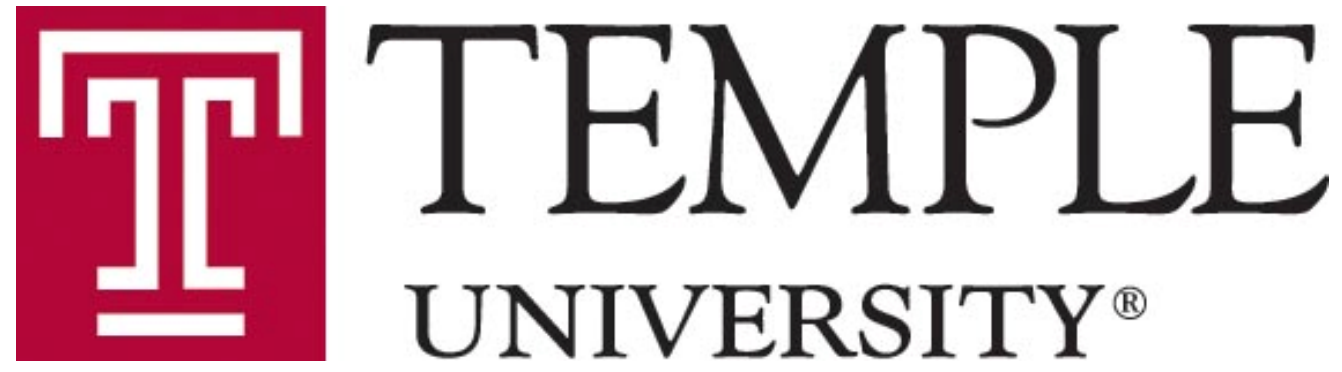

\title{
Price-Level Convergence: New Evidence from U.S. Cities
}

\author{
by \\ M. Ege Yazgan \\ Hakan Yilmazkuday \\ Department of Economics \\ DETU Working Paper 10-11
}

September 2010

1301 Cecil B. Moore Avenue, Philadelphia, PA 19122 http://www.temple.edu/cla/economics/ 


\title{
Price-Level Convergence: New Evidence from U.S. Cities
}

\author{
M. Ege Yazgan \\ Istanbul Bilgi University \\ Hakan Yilmazkuday ${ }^{1}$ \\ Temple University
}

\begin{abstract}
This paper tests the bilateral price-level convergence among 52 U.S. cities at the good level. We employ a new approach which is free of problems that arise when using an arbitrary benchmark, cross-section dependence, and heterogeneity. We find quite strong evidence in favor of convergence with significantly quick rates. This finding is surprising as the estimated median half lives are far below the half lives found in the corresponding studies for the U.S.
\end{abstract}

JEL Classification: E31, F41

Key Words: Convergence, Micro-Level Prices, PPP Puzzle

\footnotetext{
${ }^{1}$ Corresponding author: Hakan Yilmazkuday, Department of Economics, Temple University, Philadelphia, PA, 19122, USA; Tel: +1-215-204-8880; Fax: +1-215-204-8173; E-mail: hakan.yilmazkuday@temple.edu
} 


\section{INTRODUCTION}

Purchasing power parity (PPP) and law of one price (LOP) have been subject to countless empirical investigations as they constitute central roles in models of macro economy. The bulk of this empirical research consists of testing (aggregate) price-level convergence across countries; i.e., testing the stationarity of aggregate real exchange rates. After decades of scrutiny, the consensus is that aggregate price levels expressed in common currency are convergent, but convergence rates are very slow. Real exchange rates are stationary but very persistent with estimated half-lives in the range of 3-5 years (see Choi et al., 2006; Murray 2005, Frankel and Rose, 1996). This slow convergence is hard to rationalize on the basis of monetary factors and hence referred to as PPP puzzle by Rogoff (1996).

Some researchers have taken an alternative route by considering price-level convergence across regions that share a common currency. This approach provides a more controlled environment, as problems due to fluctuations in exchange rate or factor market rigidities are eliminated. By using disaggregated U.S. consumer prices, Parsley and Wei (1996) were able to show that halflife estimates range from 4 to 15 quarters, which is significantly faster than the typical estimates of the speed of convergence to PPP across countries. As a sharp contrast to this result, Cecchetti et al. (2002), estimated much larger half-life figures (amounting to 9 years!) by using consumer price indices of U.S cities. In a recent study, Crucini and Shintani (2008) utilized a large disaggregated retail price data set covering several cities and countries around the world and provided half-life estimates around 18 months across US cities. ${ }^{2}$

In these studies of price-level convergence across regions, the existence of unit root in the regional price relatives is jointly tested by conducting panel unit root tests, and half lives are calculated based on the estimates of panel unit root regressions. The main problem with these studies is that they use an arbitrary benchmark for constructing relative prices. The usual practise is to use either an arbitrarily chosen region or an aggregate measure (i.e. the average of all

\footnotetext{
${ }^{2}$ Their estimates are around 19 and 12 months for OECD and non OECD cities respectively. Similarly the evidence outside the U.S. is documented by Ceglowski (2003) for disaggregated retail prices of Canadian cities with a half life of 0.55 years; by Fan and Wei (2003) for a group of industrial materials, cars and agricultural goods from Chinese cities with the half life ranges from 0.75 month to 5.01 months; and Das and Bachattarya (2008) for consumer prices of Indian cities with an estimate of 8 to 23 months.
} 
regions) as the benchmark. Crucini and Shintani (2008) constitutes an exception; their analysis is based on panel regressions where the cross section units consist of all possible city pairs, hence is free of the arbitrary benchmark problem. However, their panel regressions assume homogenous slopes across city pairs and cross sectional independence. Clearly, both of these assumptions are unlikely to hold in practice.

This paper contributes to this literature by using an updated version of the data set used by Parsley and Wei $(1996,2001)$ and Dumond et al. (1999). To overcome the arbitrary benchmark problem, a different approach, which allows heterogeneity across city pairs and is valid even in the presence of cross sectional dependence, is used. This methodology has been developed by Pesaran (2007a). We find an overwhelming support for price-level convergence across U.S. cities irrespective of the category of the underlying good. While this result is largely consistent with what is found in the previous studies, the estimates of this paper indicate much quicker convergence rates than those previously found.

\section{DATA}

The data set includes 48 final goods and service prices obtained for 52 U.S. cities. The data are provided by American Chamber of Commerce Researchers Associations (ACCRA) on a quarterly basis and cover the period 1990q1 through 2007q4 (totally 72 quarters). In the original form, the data provided by ACCRA include 75 goods and 632 cities. However, since there are several missing observations in the original data, the number of missing observations is reduced to an "acceptable" figure. To do that, for a typical good in a typical city, a price series is not included in the analysis if it contains more missing observations than 5 percent of the period (i.e., if it is more than 4 observations). When price series are filtered according to this rule, the number of price series left in the analysis is reduced to 48 goods from 52 cities and 28 states which cover almost half of U.S. ${ }^{3}$

\footnotetext{
${ }^{3}$ After filtering, if there are any missing observations in the remaining price series, they have been completed by linear extrapolation. The data have also been seasonally adjusted by using X11 method of U.S. Bureau of Census. The detailed explanations about the goods and their origins are available upon request. More detailed information of the ACCRA data set can be found in http://www.coli.org
} 


\section{CONVERGENCE ANALYSIS}

To formally test the convergence of relative prices across U.S. cities, we use the pair-wise approach recently developed by Pesaran (2007a). ${ }^{4}$ As indicated above, so far, the analysis of relative price convergence has been conducted by applying unit root tests to relative prices measured with respect to a reference region/city. This approach is obviously more practical, but is not invariant to the choice of the benchmark country/region and, as a result can lead to misleading conclusions. However, as shown by Pesaran (2007a), a formal test of convergence can be developed by focusing on pair-wise relative prices, without choosing a reference city or region.

Convergence requires $(\log )$ prices to be cointegrated with the cointegrating vector of the form $(1,-1)$, i.e., the difference between them, $q_{i j t}=p_{i t}-p_{j t}, i=1, \ldots, N-1$ and $j=i+1, \ldots, N$ should be stationary (not having unit root) for all $N(N-1) / 2$ possible relative prices. Following Pesaran (2007a), to analyze price convergence across 52 U.S. cities, the unit-root of all $N(N-1) / 2$ possible relative price pairs, $q_{i j t}$, are examined, for all $i, j$. Therefore, for each of the 48 goods, the following ADF unit root test is run using 1326 relative price pairs:

$$
\Delta q_{t}=\mu+\beta q_{t-1}+\sum_{l=1}^{m} \gamma_{l} \Delta q_{t-l}+\varepsilon_{t}
$$

Under the null of non-convergence, the fraction of relative price pairs, for which the unit-root hypothesis is rejected, is expected to be close to the size of the unit-root test applied to the individual relative price pairs. Although, the underlying individual unit-root tests are not crosssectionally independent, under the null of non-convergence, the fraction of the rejections converges to $\alpha$, as $N$ and $T \rightarrow \infty$, where $\alpha$ is the size of the underlying unit-root test. Therefore, this proportion can consistently be estimated even in the presence of cross sectional dependence.

\footnotetext{
${ }^{4}$ Although Pesaran's approach is developed with a specific reference to convergence in output and growth, naturally, it can be used in the convergence analysis for relative prices as well as any other variables.
} 
To analyze the rate of convergence, the approximate half-life of a shock to $q_{i j t}$ is calculated as $-\ln (2) / \ln (1+\beta)$ for each of the 48 goods using 1326 possible relative price pairs.

\section{RESULTS}

Tables 1 summarizes the results of the fractions of rejections unit root tests applied to 1326 relative price pairs for 48 goods. Instead of presenting the results for each good separately, they are tabulates in groups. Table 1 displays the results for all 48 goods: 16 perishable, 16 nonperishable and 16 non-tradable (services) goods. This is the same categorization as in Parsley and Wei (1996), in which the tradables are contained under two sub-groups as perishable and non perishables.

The numbers in the cells of the tables refer to the portions of pairs for which the unit-root hypothesis of ADF tests are rejected 5 and 10 percent significance levels. On the other hand, for KPSS test, they refer to the proportion of pairs for which the null hypothesis of stationarity is not rejected $^{5}$. The results are entirely in favour of convergence hypothesis of price levels for all types of goods. The rejection (ADF) and non-rejection (KPSS) frequencies are well above the significance levels. In fact, in some cases, they are well above 80 percent. $^{6}$

The summary statistics of the distribution of half-life estimates are also given in Table $1 .^{7}$ The median estimates indicate, surprisingly, quicker rates of convergence. A median (AIC) estimate of half life for all type of goods is 1.64 quarters, which is a significantly smaller figure than those

\footnotetext{
${ }^{5}$ For ADF tests, in the tables rejection frequencies that greatly exceed a nominal size of say 0.05 (or 0.10 ) would be taken as evidence against the null of convergence. Conversely, rejection frequencies that are less than the nominal size value will be taken as evidence in favor of the null. To keep the same principle for all tests we present nonrejection frequencies for KPSS test.

6 To strengthen the results, we have also adopted the approach of Crucini and Shintani (2008) by running panel unit root tests for each of the 48 goods in which the cross section units consist of all the relative prices of 1326 city pairs. To account for the cross-section dependence, CIPS test of Pesaran (2007b) has been used, which simply eliminates the cross section dependence by augmenting the individual ADF (CADF) regressions with cross section averages. It is found that unit root in relative prices are rejected for all goods, for the tests with relatively low lags and for a large proportion of goods for the higher CADF lags. These results are available upon request.

7 The half lives have been calculated according to the ADF (AIC) test. For each good, the negatively valued half-life estimates (non-converging pairs) have been removed from the distribution of 1326 half-life estimates.
} 
of the above mentioned studies. Traded goods exhibit even quicker convergence rates nearly as below as 1.37 quarters for perishables. The half-life estimates of nontraded goods indicate slower convergence with 2.75 quarters; even this number constitutes a significantly smaller estimate than the previous ones.

\section{CONCLUSION}

This paper tests the price-level convergence among 52 U.S. cities at the good level by using a new approach which is free of problems arising from arbitrary benchmark, cross-section dependence, and heterogeneity. We find strong evidence in favor of convergence with significantly quicker rates than those of previous studies. The difference may be due to the difference either in methodologies or in data sets. Although Parsley and Wei (1996) have the same data coverage and source as this paper, their estimates belong to a much earlier period than those of this study. Crucini and Shintani (2008), being one of the most updated study, use a different data set including much fewer U.S. cities in an annual context. The studies reporting half-life estimates as low as this paper are by Ceglowski (2003) for disaggregated retail prices of Canadian cities and by Fan and Wei (2003) for a group of industrial materials, cars and agricultural goods from Chinese cities. 
Table 1

\begin{tabular}{|c|c|c|c|c|c|c|c|c|c|c|}
\hline \multicolumn{6}{|c|}{ ALL GOODS } & \multicolumn{5}{|c|}{ PERISHABLE GOODS } \\
\hline & \multicolumn{5}{|c|}{ Convergence ( $5 \%$ significance level) } & \multicolumn{5}{|c|}{ Convergence (5\% significance level) } \\
\hline & $\mathrm{ADF}$ & ADF-GLS & ADF-WS & $\underline{\mathrm{KPSS}}$ & & $\underline{\mathrm{ADF}}$ & DF-GLS & ADF-WS & KPSS & \\
\hline AIC & 0.491 & 0.588 & 0.585 & 0.584 & & 0.506 & 0.623 & 0.612 & 0.566 & \\
\hline \multirow[t]{3}{*}{ SBC } & 0.689 & 0.752 & 0.761 & - & & 0.696 & 0.770 & 0.772 & - & \\
\hline & \multicolumn{5}{|c|}{ Convergence (10\% significance level) } & \multicolumn{5}{|c|}{ Convergence (10\% significance level) } \\
\hline & $\underline{\mathrm{ADF}}$ & ADF-GLS & ADF-WS & $\underline{\text { KPSS }}$ & & $\underline{\mathrm{ADF}}$ & DF-GLS & ADF-WS & $\underline{\text { KPSS }}$ & \\
\hline AIC & 0.554 & 0.685 & 0.664 & 0.691 & & 0.576 & 0.700 & 0.686 & 0.675 & \\
\hline \multirow[t]{3}{*}{ SBC } & 0.733 & 0.805 & 0.808 & - & & 0.754 & 0.833 & 0.814 & - & \\
\hline & \multicolumn{5}{|c|}{ Rate of Convergence (half lives) } & \multicolumn{5}{|c|}{ Rate of Convergence (half lives) } \\
\hline & Min & $\mathrm{q} 1$ & Median & $\mathrm{q} 3$ & $\underline{\max }$ & Min & $\mathrm{q} 1$ & median & $\mathrm{q} 3$ & Max \\
\hline AIC & 0.119 & 1.012 & 1.642 & 2.821 & 355.528 & 0.106 & 0.758 & 1.370 & 2.464 & 219.134 \\
\hline SBC & 0.127 & 0.826 & 1.400 & 2.355 & 140.203 & 0.111 & 0.611 & 1.065 & 1.969 & 110.891 \\
\hline
\end{tabular}

\begin{tabular}{|c|c|c|c|c|c|c|c|c|c|}
\hline & \multicolumn{5}{|c|}{ NON-PERISHABLE GOODS } & \multicolumn{4}{|c|}{ NON-TRADABLE GOODS (SERVICES) } \\
\hline & \multicolumn{5}{|c|}{ Convergence ( $5 \%$ significance level) } & \multicolumn{4}{|c|}{ Convergence ( $5 \%$ significance level $)$} \\
\hline & $\overline{\mathrm{ADF}}$ & ADF-GLS & ADF-WS & KPSS & & $\overline{\mathrm{ADF}}$ & ADF-GLS & ADF-WS & $\underline{\mathrm{KPSS}}$ \\
\hline AIC & 0.533 & 0.639 & 0.617 & 0.544 & & 0.349 & 0.473 & 0.464 & 0.641 \\
\hline \multirow[t]{3}{*}{ SBC } & 0.728 & 0.819 & 0.790 & - & & 0.475 & 0.590 & 0.574 & - \\
\hline & \multicolumn{5}{|c|}{ Convergence ( $10 \%$ significance level) } & \multicolumn{4}{|c|}{ Convergence (10\% significance level } \\
\hline & $\overline{\mathrm{ADF}}$ & ADF-GLS & ADF-WS & $\underline{\text { KPSS }}$ & & $\overline{\mathrm{ADF}}$ & ADF-GLS & ADF-WS & $\underline{\mathrm{KPSS}}$ \\
\hline AIC & 0.600 & 0.736 & 0.691 & 0.648 & & 0.436 & 0.579 & 0.551 & 0.750 \\
\hline \multirow[t]{3}{*}{ SBC } & 0.784 & 0.872 & 0.845 & - & & 0.565 & 0.686 & 0.652 & - \\
\hline & \multicolumn{5}{|c|}{ Rate of Convergence (half lives) } & \multicolumn{4}{|c|}{ Rate of Convergence (half lives) } \\
\hline & $\min$ & $\mathrm{q} 1$ & Median & $\mathrm{q} 3$ & $\underline{\max }$ & $\underline{\min }$ & $\mathrm{q} 1$ & median & $\underline{\operatorname{Max}}$ \\
\hline AIC & 0.106 & 0.884 & 1.452 & 2.566 & 171.514 & 0.154 & 1.560 & 2.756 & 5.3351008 .304 \\
\hline SBC & 0.119 & 0.764 & 1.208 & 2.113 & 69.050 & 0.170 & 1.338 & 2.495 & 4.684520 .563 \\
\hline
\end{tabular}

Note: ADF is a standard Dickey-Fuller unit root test, ADF-GLS is Elliott et al. (1996) test, ADF-WS is Park and Fuller's (1995) weighted symmetric test, and KPSS is Kwiatkowski et al. (1992) test. The table shows the portions of pairs for which the unit-root hypothesis of $\operatorname{ADF}(p), \operatorname{ADF}-\mathrm{GLS}(p), \operatorname{ADF}-\mathrm{WS}(p)$ tests are rejected, where $p$ is the number of lags determined by Akaike Information Criteria (AIC) or Schwartz Bayesian Information Criterion (SBC), and portions of pairs for which the stationarity hypothesis of KPSS test is rejected. The window lags used are chosen approximately as $0.75\left({ }^{3} \sqrt{T}\right)$ where $T$ is the sample size. 


\section{References:}

- Cecchetti, Stephen G., Nelson C. Mark, and Robert J. Sonora (2002). "Price Index Convergence among United States Cities." International Economic Review, 43(4): 1081-99.

- Ceglowski, Janet (2003). "The Law of One Price: Intranational Evidence for Canada."Canadian Journal of Economics, 36(2): 373-400.

- Choi, C.Y., Mark, N.C., Sul, D., 2006. "Unbiased estimation of the half-life to PPP convergence in panel data", Journal of Money, Credit and Banking 38 (4), 921-938.

- Crucini, M.J., and Shintani, M. (2008) "Persistence in law of one price deviations: Evidence from micro-data", Journal of Monetary Economics, 55(3): 629-644.

- Das, S., and Bhattacharya, K. (2008) "Price convergence across regions in India", Empirical Economics, 34:299-313.

- Dumond, M.J., Hirsch, B.T. and Macpherson, D.A. (1999) "Wage Differentials Across Labor Markets And Workers: Does Cost Of Living Matter?” Economic Inquiry 37(4): 577-598

- Elliott, G., T.J. Rothenberg and J.H. Stock (1996), "Efficient Tests for an Autoregressive Unit Root", Econometrica, 64, 813-836.

- Fan, C.S., and Wei S. (2003) "The Law of One Price: Evidence from the Transitional Economy of China", unpublished paper.

- Frankel, J.A., Rose, A.K., 1996. “A panel project on purchasing power parity: mean reversion within and between countries". Journal of International Economics 40 (1-2), 209224.

- Kwiatkowski, D., Phillips, P.C.B., Schmidt, P. and Y. Shin (1992), "Testing the null hypothesis of stationarity against the alternative of a unit root: how sure are we that economic time series have a unit root?", Journal of Econometrics, 44: 159-178.

- Murray, C.J., Papell, D.H., 2005. "Do panels help solve the purchasing power parity puzzle?" Journal of Business and Economic Statistics 23 (4), 410-415.

- Park, H. J., and W. A. Fuller (1995), "Alternative Estimators and Unit Root Tests for the Autoregressive Process", Journal of Time Series Analysis, 16, 449-459.

- Parsley, David and Shang-jin Wei (1996). "Convergence to the Law of One Price without Trade Barriers or Currency Fluctuations." Quarterly Journal of Economics, 111(4): 12111236.

- Parsley, David and Shang-jin Wei (2001). "Explaining the border effect: the role of exchange rate variability, shipping costs, and geography." Journal of International Economics, 55: 87105.

- Pesaran, M.H., (2004), "General diagnostic tests for cross section dependence in panels", CESifo Working Papers, No.1233.

- Pesaran, M.H. (2007a), "A pair-wise approach for testing output and growth convergence", Journal of Econometrics, 138:312-355

- Pesaran, M.H., (2007b), "A simple panel unit root test in the presence of cross section dependence", Journal of Applied Econometrics, 22, 265-312.

- Rogoff, K., (1996), “The Purchasing Power Parity Puzzle”, Journal of Economic Literature, 34: 647-668. 